\title{
Immunohistochemical Expression of Estrogen And Progesterone Receptors in Neuroendocrine Breast Carcinomas
}

\author{
Naser M.anwer, M.d.*- Ahmed H. Abdel-Rahman, M.D.** Ahmed S. Salem, \\ M.d**- Abdel- Ghany Awad Essa, M.D.***
}

Departments of Pathology*, ** and General Surgery*** Al-Azhar University (Cairo) and (Assuit)

\begin{abstract}
:
Neuroendocrine (NE) breast carcinomas are defined by the diffuse expression of NEmarkers. They may coexpress NE and non-NE substances such as glycoproteins and apocrine protein "divergent differentiation". In the present study, twenty NE-breast carcinomas, expressing chromogranin A (CgA) and neurone specific enolase (NSE) were selected from a series of two hundreds retrospective breast carcinomas, in addition to ten normal breast tissue biopsies taken as control. The NE-tumors were graded into G1, G2 \& G3 and were divided according to the mucin expression into group 1 (Mucinous NE-tumors) and group 2 (other variants that did not express mucin). Each group included 10 cases.

Immunohistochemistry was applied to paraffin sections for investigating CgA \& NSE expression as well as estrogen and progesterone receptors (ER \& PR) status. Group 1 tumors fell within lower grades than those of group 2 . Moreover, ER \& PR positivity rates were $75 \%$ $\& 65 \%$ respectively. Also, ER expression was not significantly correlated with NE phenotype $(\mathrm{P}=0.14)$ or with grade $(\mathrm{P}=0.24)$ while $\mathrm{PR}$ expression was significantly higher in group 1 than in group $2(\mathrm{P}=0.02)$ and in $\mathrm{G} 1, \mathrm{G} 2$ than $\mathrm{G} 3(\mathrm{P}=0.04)$ Both steroid receptors coexpression was significantly higher in group 1 than in group 2 tumors $(P=0.05)$ and found in G1 and G2 but not in G3 tumors. Finally, ER and PR were coexpressed, although fewer \& sporadic, in all control biopsies (100\%) compared to its presence only in $45 \%$ of the studied NE tumors.

The study concluded that NE-breast tumors, producing high level of NE markers were specific entity and those coexpressing ER \& PR might possess a multidirectional differentiation. Moreover, it may appear quite necessary to define estrogen \& progesterone receptors status in NE breast carcinomas so as to decide, whether or not to try hormone therapy as adjuvant treatment modality in these tumors.
\end{abstract}

Key words: Immunohistochemistry, Estrogen Receptors, Progesterone Receptors, Neuroendocrine, Breast Carcinoma

\section{Introduction:}

Breast carcinomas are a multifaceted entity that may show various types of differentiation. In breast carcinomas of usual type, focal neuroendocrine and apocrine differentiations are occasionally detected in scattered cells by the immunocytochemical expression of NE and apocrine markers ${ }^{(1-3)}$. In addition, scattered hormone-producing cells have been descrybed in two cases of apocrine breast carcinoma $^{(4)}$.

The term "neuroendocrine" was applied to a heterogenous series of breast carcinomas while in other non-endocrine organs, such as lung ${ }^{(5)}$ and prostate ${ }^{(6)}$, this term defined tumors uniformly and homogenously positive for NE markers and correlated to a specific clinical evolution ${ }^{(7)}$. As a consequence, the NEdifferentiated breast carcinomas were confined to those with a relevant percentage $(\geq 50 \%)$ of cells expressing NEmarkers ${ }^{(8)}$. Moreover, all the existing studies on the clinical evolution of NEbreast carcinomas regarded them as a single entity ${ }^{(1,3,7,8)}$. Small cell carcinomas 
are considered as undifferentiated variety of the NE-breast carcinomas ${ }^{(9)}$.

A relatively common phenomenon of diagnostic interest in NE breast carcinomas, is the presence of a divergent differentiation which indicates the ability of a tumor to produce both $\mathrm{NE}$ and non-NE substances such as glycoproteins. Mucin production is generally indeed a common feature in NE-breast carcinomas and has been correlated to a low aggressiveness of tumors $^{(10)}$.

Normally, the ER is expressed in less than $20 \%$ of the luminal epithelial and myoepithelial cells as well as being detectable in fibroblasts and other stromal cells $^{(11)}$. Also, the PR is expressed in less than $20 \%$ of luminal epithelial cells but not elsewhere in the human breast ${ }^{(12)}$. All cells normally expressing the PR have been found to contain also the ER, however, these steroid receptor-expressing cells are separate from, but often adjacent to, those labelled with markers of proliferation $^{(13)}$.

The sex steroid hormones are assumed normally to control the proliferative activity of the luminal epithelial cells indirectly in a mechanism that the receptor-containing cells act as sensors which secrete positive or negative paracrine and /or juxtacrine growth factors, according to the prevailing estradiol/progesterone concentrations, to influence the activity of nearly division-competent cells. This would attenuate the sensitivity of the mammary epithelium to steroid hormones such that proliferation will occur only when a sufficient concentration of positive growth factors has accumulated ${ }^{(12)}$.

Since the breast is one of the target tissues of sex steroid hormones and since the presence of ER \& PR within a tissue generally considered a prerequisite for this tissue to manifest long term response to hormonal therapy ${ }^{(7)}$, this study evaluates the steroid receptor levels in NE-breast carcinomas and investigates the influences of the histologic grade as well as ER \& PR status on the biological evolution of such tumors.

\section{Material and Methods:}

The material of this work consisted of a sum of twenty NE-breast carcinoma cases selected from a series of two hundreds retrospective breast carcinoma biopsies obtained from Al-Azhar University Hospitals during the peroid (2000-2003). The NE-tumors were graded using the Elston and Ellis grading system $^{(14)}$, which considered the nuclear pleomorphism, the number of mitoses and the formation of tubules within the tumor. In addition, ten biopsies of normal nonneoplastic breast tissues were taken as control. Expression of $\mathrm{CgA}$ and NSE as well as estrogen and progesterone receptors (ER \& PR) status were investigated in all studied cases.

Formalin-fixed, paraffin-embedded blocks were sectioned at $5 \mu$ thickness. One section was stained with Hematoxylin and Eosin, for routine histopathologic study. Additional four sections were used for immunohistochemical (IHC) study to investigate the expression of NE-markers (namely $\mathrm{CgA} \& \mathrm{NSE}$ ) as well as ER \& PR immunoreactivity. Mouse monoclonal primary antibodies for CgA (LVRB 9003 R1- Dako), ER (A 589-Dako), ER (1D5-N 1595-Dako) and PR (1A6-N 1595-Dako) were applied, each one on a section. Antigen retrieval was done by microwave heating in citrate solution (BiogenexNeufahrn, Germany). Secondary antimouse antibodies using peroxidase labelled biotin streptavidin complex detection system (Dako, Copenhagen, Denmark) for CgA, NSE, ER and PR were applied. Counterstaining was performed using Mayer's Hematoxylin (Biogenex, Cat, No. 94583). The age as well as other clinicopathologic data were obtained from the patients' files.

Positive reaction for $\mathrm{CgA} \& \mathrm{NSE}$ appeared as brownish cytoplasmic granular staining of the tumors cells while positive reaction for ER \& PR appeared as brownish nuclear staining of these cells. For evaluation of IHC results, the following limits were used in consideration of positive reaction: $\geq 50 \%$ for each of $\mathrm{CgA} \& \mathrm{NSE}, \geq 20 \%$ for each of ER \& PR. The intensity of nuclear staining for ER \& PR were scored as: 0(-) negative, $1(+)$ : Weakly positive (presence of few weakly stained positive cells), $2(++)$ : Moderately positive (numerous positive cells and occasionally positive cell clusters with moderate intensity) \& $3(+++)$ 
Strongly positive (multiple clusters or diffuse intense positive staining).

\section{Statistical Analysis:}

The association of ER and PR with the histological type and grade were analyzed using a X2 test. All data were analyzed for statistical significance by the Pearson's Chi-square tests. A $P$ value $\leq 0.05$ was considered a statistically significant, $\leq$ 0.01 was a highly significant and $\leq 0.001$ was a very highly significant one.

\section{Results:}

This study examined 20 NE-breast carcinoma cases showing immunoreactivity for CgA (Fig. 1) \& NSE (Fig. 2) in $50-75 \%$ of its tumor cells, appearing as brownish cytoplasmic immunostaining. They were divided morphologically into two groups; group 1: Mucinous carcinomas (10/20-50\%) showing a variable amount of extracellular mucin ranged from small pools (6 cases, Fig. 3) to large lakes (4 cases) and group 2: Other NE-variants which showed no mucin secretion $(10 / 20-$ $50 \%$ ) including solid cohesive (4 cases), alveolar (3 cases, Fig.4) \& poorly differentiated ( 3 cases) (Table 1). In addition, 10 normal breast tissue biopsies were used as control. The patient's age ranged from 52 into 72 years (mean 62.3 years). Regarding the Elston and Ellis grading system ${ }^{(14)}$, the NE-tumors showed no tubular formation and their histologic grade was significantly influenced by the number of mitoses $(\mathrm{P}=$ 0.0039) that ranged from $4 / 10$ high power fields (HPF) in well differentiated (G1) to 25/10 HPF in poorly differentiated (G3) tumors. In the intermediate differentiated (G2) tumors, the mitotic index was 10/10 HPF. Accordingly, six (6/20-30\%) were $\mathrm{G} 1$, ten $(10 / 20-50 \%)$ were $\mathrm{G} 2$ and four cases $(4 / 20-20 \%)$ were G3. The patients with poorly differentiated tumors didn't have non-mammary carcinomas. Also, the small cell variety, considered as undiffer- entiated, was excluded in the present study. All group 1 cases fell within G1 and G2 while groups 2 cases fell within G2 and G3 (Table 2).

Positive immunoreactivity for ER \& PR appeared as brownish nuclear staining in $45-60 \%$ of the malignant cells. Positive ER immunoreactivity appeared in fifteen out of the NE- carcinomas cases $(15 / 20$ $75 \%)$ including eight group 1 cases $(8 / 10$ $80 \%$ ), five of which were G1 \& three were G2 (Fig. 5) as well as seven group 2 cases $(7 / 10-70 \%)$, three of which were solid cohesive (G2), two were alveolar (G2) (Fig. 6) and two were poorly differentiated (G3) variant. Among the fifteen ER positive NE tumors; six were strongly positive $(3+)$, four were moderately positive $(2+)$ and five were weakly positive (1+) (Table 3$)$.

Positive PR immunoreactivity appeared in thirteen out of the NE-cases (13/20$65 \%)$ including eight group 1 cases $(8 / 10$ $80 \%$ ), five of which were G1 \& three were G2 in addition to five group 2 cases (5/10$50 \%$ ), two of which were solid cohesive (G2), two were alveolar (G2, Fig. 7) and one was poorly differentiated (G3) variant. Among the thirteen PR positive NEtumors, six were strongly positive (3+), six were moderately positive $(2+)$ and one was weakly positive (1+) (Table 4).

$\mathrm{ER}+/ \mathrm{PR}+$ phenotype was noticed in nine cases (9/20-45\%); seven of which were group 1 including four G1 \& three G2 cases and two were group 2 including one solid cohesive (G2) \& one alveolar (G2) case. None of the G3 NE tumors in the present study expressed ER+/PR+ phenotype (Table 5).

All control cases showed few insignificant $\mathrm{CgA}$-or NSE-positive cells and also revealed disregarded, sporadic ER-\& PR- positive cells.

Table (1): Histotypes of the studied NE-breast carcinomas

\begin{tabular}{|c|c|c|}
\hline His to type & No. & $\%$ \\
\hline Group 1: Mucinous & 10 & 50 \\
\hline Group 2: Others & & \\
\hline - Solid cohesive & 4 & 20 \\
\hline - Alveolar & 3 & 15 \\
\hline - $\quad$ Poorly differentiated & 3 & 15 \\
\hline Total & 20 & 100 \\
\hline
\end{tabular}


Table (2): Histologic types \& grades of the studied NE breast carcinomas $(n=20)$ :

\begin{tabular}{|l|c|c|c|}
\hline \multicolumn{1}{|c|}{ Histo type } & \multicolumn{3}{|c|}{ Grades (G) } \\
\cline { 2 - 4 } & G1 & G2 & G3 \\
\hline Group 1: Mucinous & 6 & 4 & 0 \\
Group 2: Others: & 0 & 3 & 1 \\
$\quad$ Solid cohesive & 0 & 3 & 0 \\
Alveolar & 0 & 0 & 3 \\
\hline \multicolumn{1}{|c|}{ Poorly differentiated } & & 0 & $\mathbf{4}(\mathbf{2 0} \%)$ \\
\hline \multicolumn{1}{|c|}{ Total } & $\mathbf{6 ( 3 0 \% )}$ & $\mathbf{1 0}(\mathbf{5 0 \%})$ &
\end{tabular}

Table (3): ER expression in the studied NE-breast carcinomas $\quad(n=20)$ :

\begin{tabular}{|c|c|c|c|c|c|}
\hline \multirow[b]{2}{*}{ Histotype and Grade (G) } & \multicolumn{5}{|c|}{ ER-positive cases (No; $=15 / 20-75 \%)$} \\
\hline & No & $\%$ & Weak (1+) & Mod. (2+) & Strong (3+) \\
\hline $\begin{array}{l}\text { Group 1: Mucinous }(\mathrm{n}=10) \text { : } \\
\text { G1 }\end{array}$ & $5 / 6$ & 83.3 & 1 & 1 & 3 \\
\hline G2 & $3 / 4$ & 75 & 1 & 1 & 1 \\
\hline Total & $8 / 10$ & 80 & 2 & 2 & 4 \\
\hline $\begin{array}{l}\text { Group 2: Others }(\mathrm{n}=10): \\
\text { Solid cohesive }(\mathrm{G} 2)\end{array}$ & $3 / 4$ & 75 & 1 & 1 & 1 \\
\hline Alveolar (G2) & $2 / 3$ & 66.7 & 0 & 1 & 1 \\
\hline Poorly differentiated (G3) & $2 / 3$ & 66.7 & 2 & 0 & 0 \\
\hline Total & $7 / 10$ & 70 & 3 & 2 & 2 \\
\hline
\end{tabular}

Mod. $=$ Moderate $; \quad$ ER $=$ Estrogen Receptors;

No; = Number of immunoreactive tumors / examined tumors.

Table (4): PR expression in the studied NE breast carcinomas $(n=20)$ :

\begin{tabular}{|l|c|c|c|c|c|}
\hline \multirow{2}{*}{ Histotype and Grade (G) } & \multicolumn{5}{|c|}{ PR - positive cases (No; = 13/20 - 65\%) } \\
\cline { 2 - 6 } & No & $\mathbf{\%}$ & Weak (1+) & Mod. (2+) & Strong (3+) \\
\hline Group 1: Mucinous (n =10); & & & & & \\
G1 & $5 / 6$ & 83.3 & 0 & 3 & 2 \\
G2 & $3 / 4$ & 75 & 0 & 2 & 1 \\
\hline \multicolumn{1}{|c|}{ Total } & $\mathbf{8 / 1 0}$ & $\mathbf{8 0}$ & $\mathbf{0}$ & $\mathbf{5}$ & $\mathbf{3}$ \\
\hline Group 2: Others (n =10): & & & & & \\
Solid cohesive (G2) & $2 / 4$ & 50 & 0 & 0 & 2 \\
Alveolar (G2) & $2 / 3$ & 66.7 & 0 & 0 & 0 \\
Poorly differentiated (G3) & $1 / 3$ & 33.3 & 1 & $\mathbf{1}$ & $\mathbf{3}$ \\
\hline \multicolumn{2}{|c|}{ Total } & $\mathbf{5 / 1 0}$ & $\mathbf{5 0}$ & $\mathbf{1}$ & $\mathbf{1}$ \\
\hline
\end{tabular}

$P R=$ Progesterone Receptors $; \quad$ Mod $=$ Moderate $;$

No; = Number of immunoreactive tumors / examined tumors.

Table (5): $\mathrm{ER}+/ \mathrm{PR}+$ phenotype in the studied NE-breast carcinomas $(\mathrm{n}=\mathbf{2 0})$

\begin{tabular}{|c|c|c|}
\hline \multirow{2}{*}{ Histotype } & \multicolumn{2}{|c|}{ ER+/PR+ Phenotype (No; 9/20-45\%) } \\
\cline { 2 - 3 } & No; & \% \\
\hline Group 1: Mucinous & 4 & 40 \\
G1 & 3 & 30 \\
G2 Total & $\mathbf{7}$ & $\mathbf{7 0}$ \\
\hline Group 2: Others (n = 10) & 1 & 10 \\
Solid cohesive (G2) & 1 & 10 \\
Alveolar (G2) & $\mathbf{2 0}$ \\
\hline Total & $\mathbf{2}$ & $\mathbf{2 0}$ \\
\hline
\end{tabular}

ER+/PR+ phenotype $=$ Estrogen and progesterone positive coexpression;

No; $=$ Number of immunoreactive tumors lexamined tumors. 


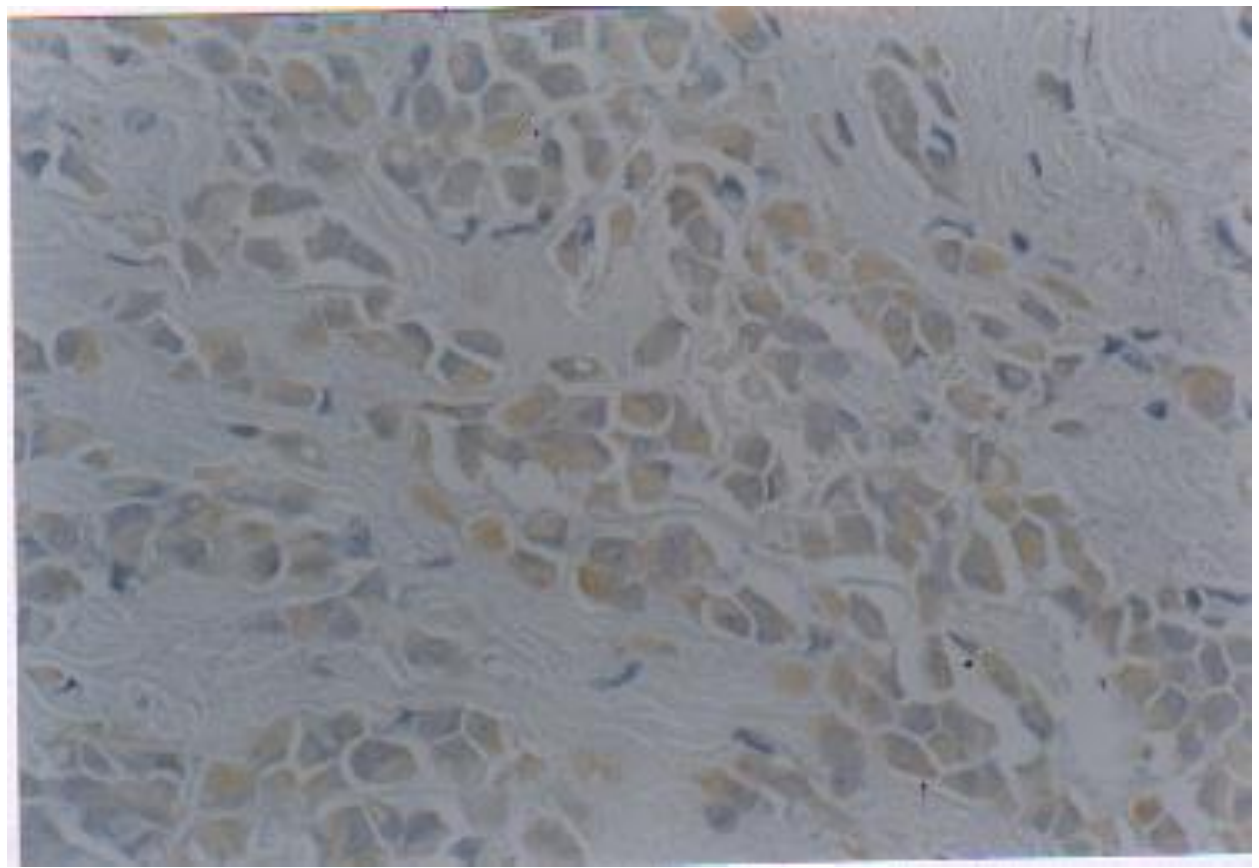

Fig. (1): Alveolar NE-breast carcinoma, grade 2, showing CgA-positive tumor cells (brownish granular cytoplasm)

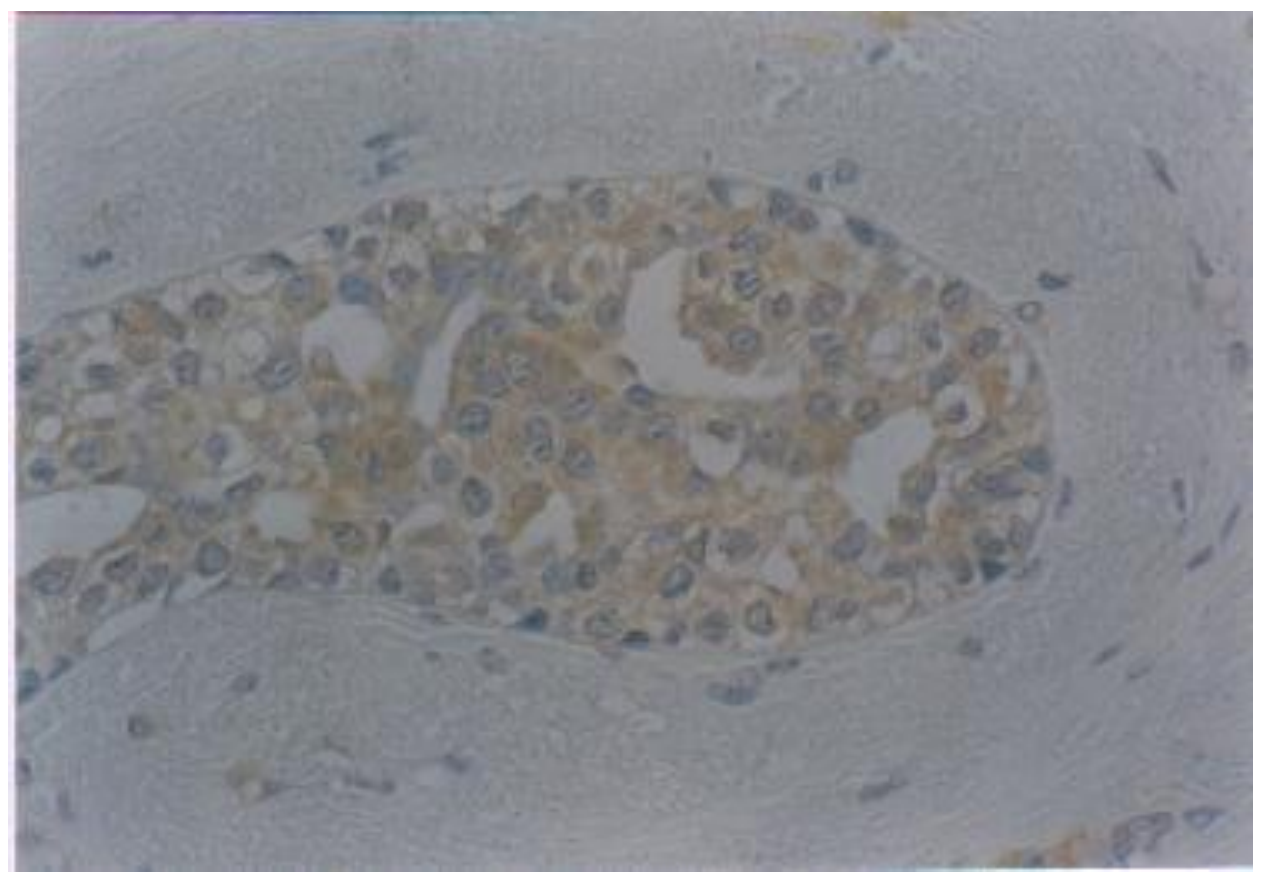

Fig. (2): Mucinous NE-breast carcinoma, grade 2, showing NSE-positive neoplastic cells (brownish granular cytoplasm)

(IP X 200). 


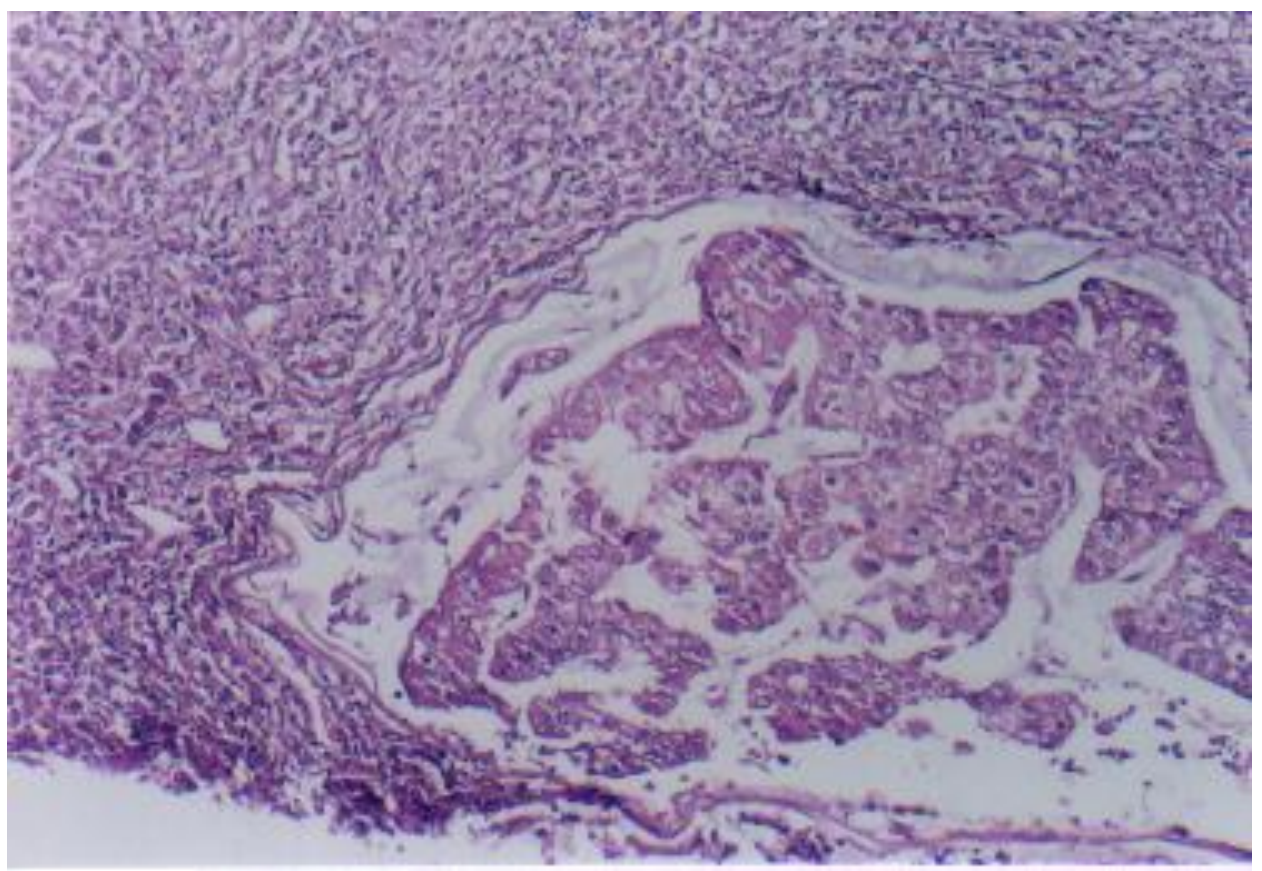

Fig. (3): Mucinous NE-breast carcinoma, grade 2, showing a cribriform sheet of malignant cells floating in a pool of mucin

$(\mathrm{H} \times \mathrm{E} \times 100)$

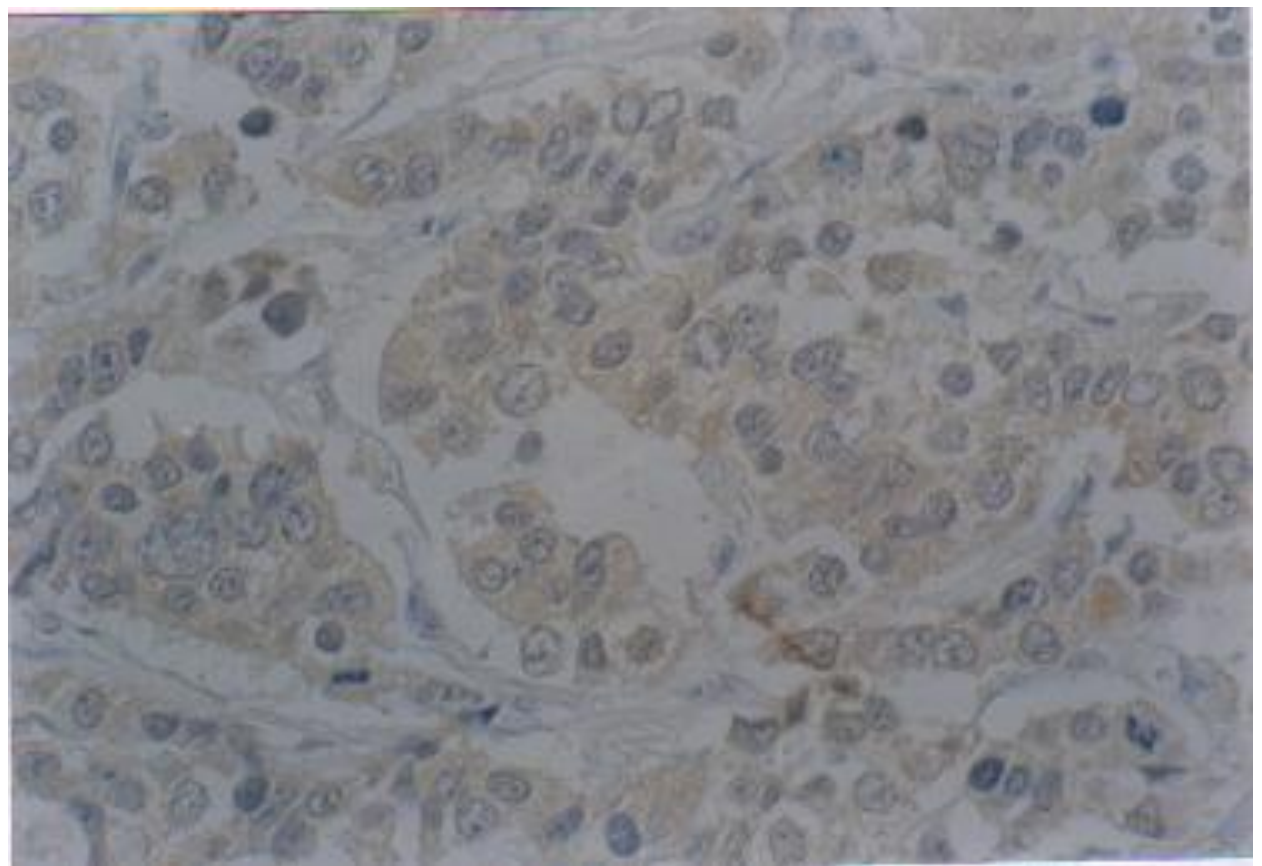

Fig. (4): Alveolar NE-breast carcinoma, grade 2, showing NSE - positive tumor cells

(IP X 400). 


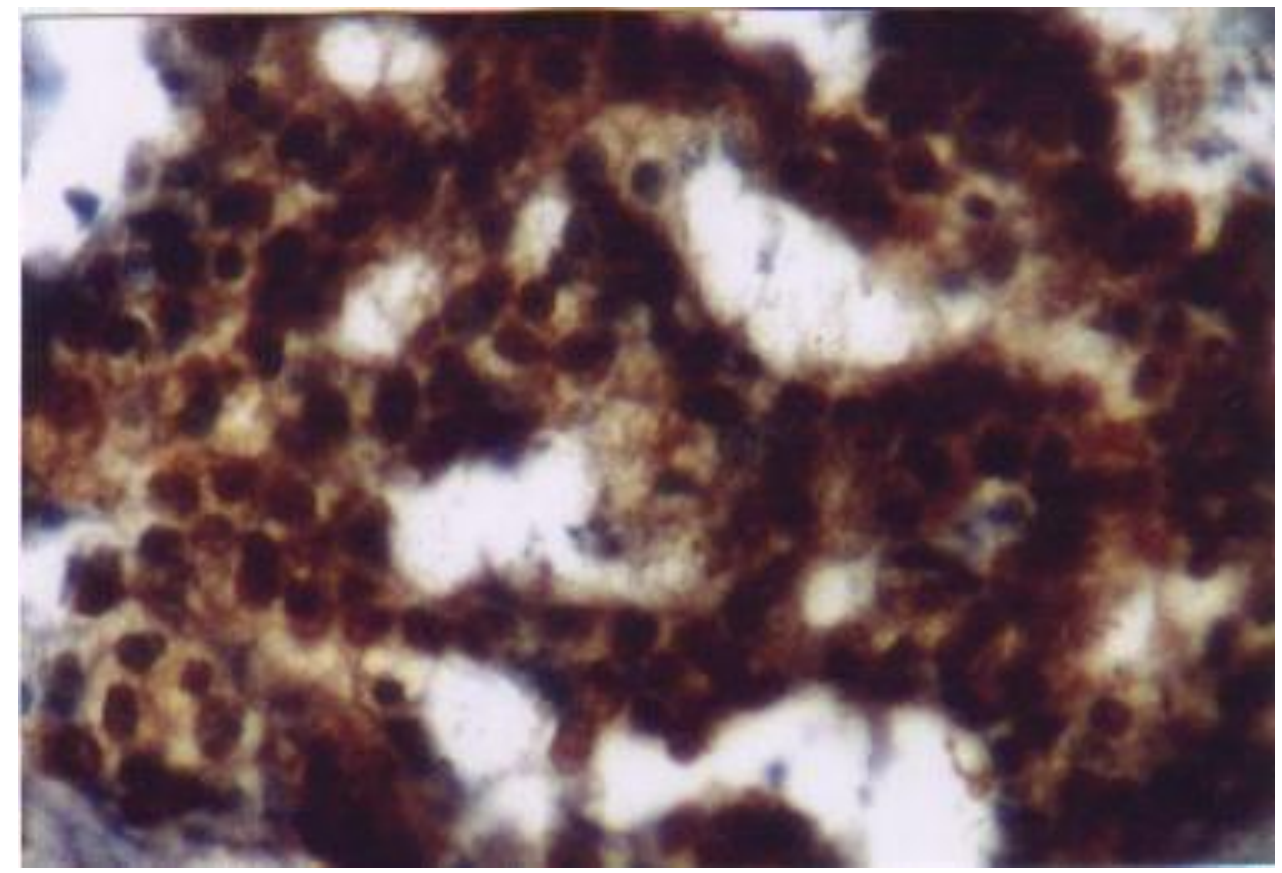

Fig. (5): Mucinous NE-breast carcinoma, grade 2, strongly positive for ER immunoreactivity.

(IP X 400).

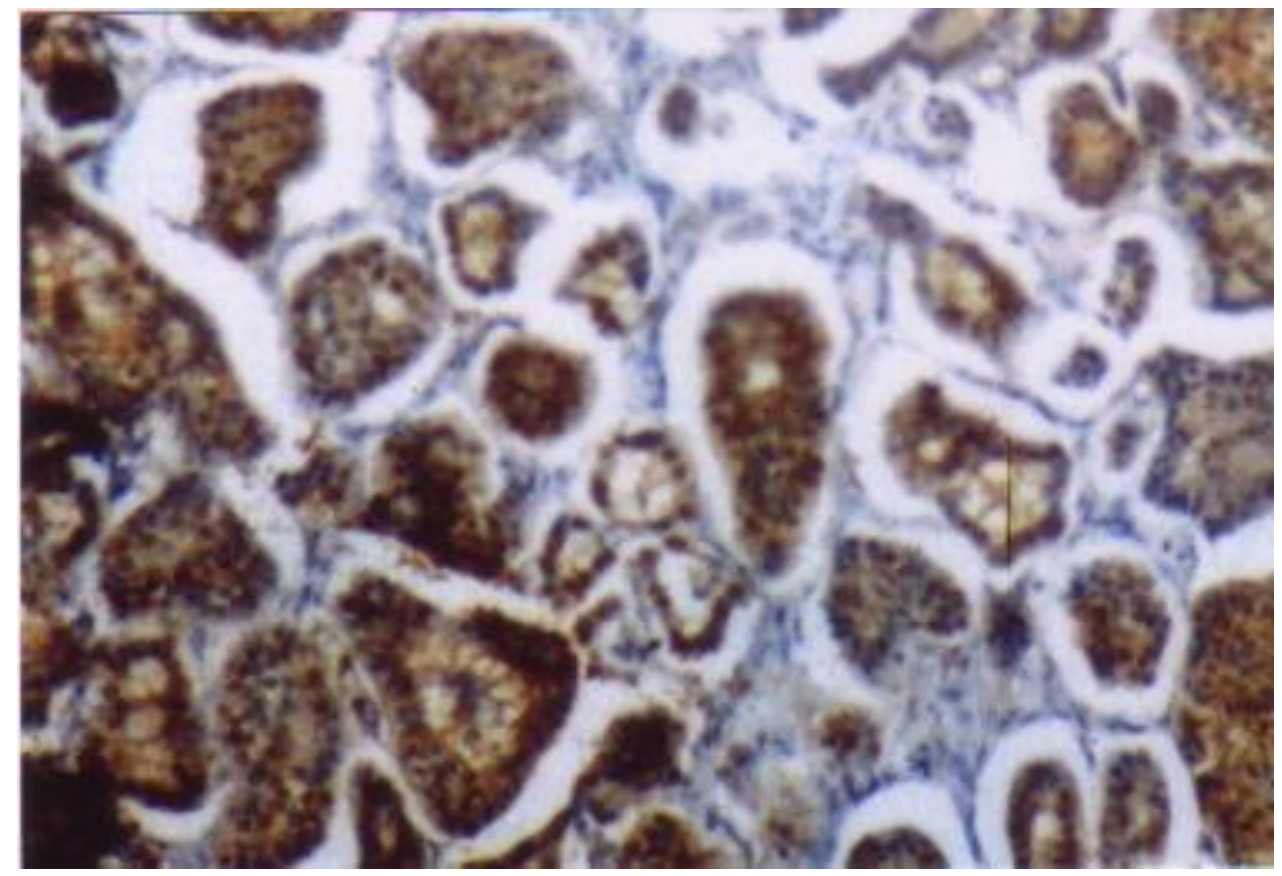

Fig. (6): Alveolar NE- breast carcinoma, grade 2, strongly positive for ER immunoreactivity (IP X 100). 


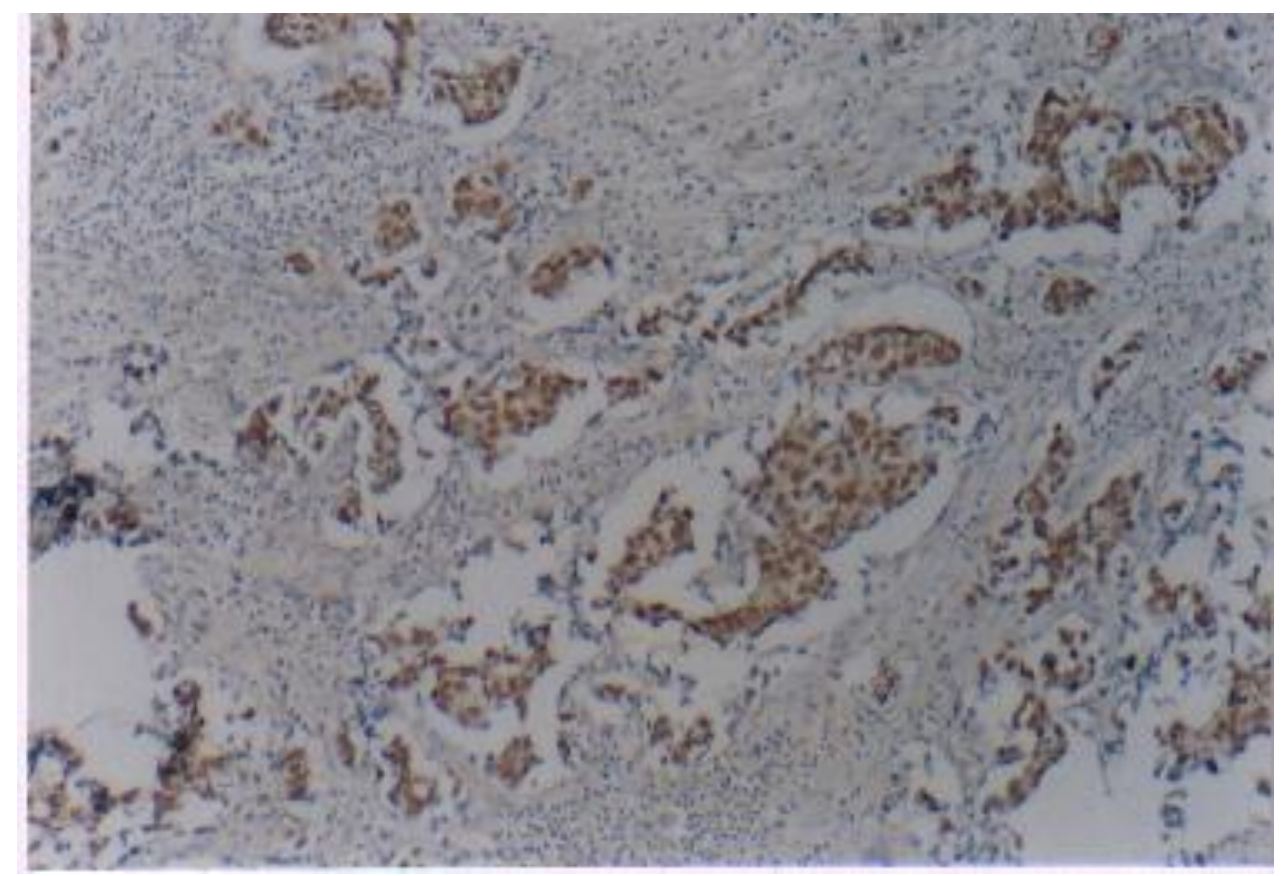

Fig. (7): Alveolar NE-breast carcinoma, grade 2, strongly positive for PR immunoreactivity

(IP X 100).

\section{Discussion and Conclusion:}

Neuroendocrine (NE) differentiation in breast carcinomas has been considered as a peculiar feature of minimal clinical significance ${ }^{(10)}$.

The immunohistochemical technique was applied in this study to demonstrate the NE-differentiation in breast carcinomas as the identification by Hematoxylin and Eosin alone was highly subjective and unreliable ${ }^{(3,15)}$.

In this work, the tumors showed immunoreactivity for CgA and NSE in 50$75 \%$ of its cells coinciding with Sapino et al., ${ }^{(8)}$ who stated that the NE-breast carcinomas are only defined when expressing NE-markers in, at least, $50 \%$ of their cells. A clinical significance of such definition as reported by Giovanella et al., ${ }^{(16)}$ relies on the fact that a marked elevation of serum $\mathrm{CgA}$ has been detected in patients affected by small $(<2 \mathrm{~cm})$ but intensely immunoreactive NE-tumors.

Our study showed that the NEphenotype of tumors was correlated with grades as the mucinous NE-tumors has lower grades than other NE-variants. This finding agreed with those of Sapino et al., (7) who mentioned that the mucinous differentiation was a favourable prognostic factor and the patients with mucinous NE- carcinomas has a significantly longer survival time than did patients with tumors of the other histologic types $(\mathrm{P}=0.05)$. They, as well, stated that the histological grading was another important prognostic parameter in NE-breast carcinomas $(\mathrm{P}=$ 0.007 ) as all G1 cases, with a low proliferative activity, survived at more than 10years of follow-up while poorly differentiated (G3) NE-tumors, with a high proliferative activity, were very aggressive.

Also, the study showed ER \& PR positivity rates of $75 \% \& 65 \%$ respectively. These figures were close to those stated by other investigators who found that ER \& PR positivity rates were $76.1 \%$ \& $64.4 \%$ respectively $^{(7)}$ and $74.8 \%$ \& $65.3 \%$ respectively ${ }^{(10)}$. Such variability in the rates may be explained by the difference in methods applied.

In the present study, ER expression was not significantly correlated with NEphenotype $(\mathrm{P}=0.13)$ or with grade $(\mathrm{P}=$ $0.24)$ while $P R$ expression was significantly higher in group 1 than in group 2 cases $(P=0.02)$ and in lower grades $(\mathrm{G} 1$ $\& \mathrm{G} 2)$ than in grade 3 tumors $(\mathrm{P}=0.04)$. Moreover, ER \& PR coexpression was significantly found more in group 1 than in group 2 cases $(\mathrm{P}=0.05)$ and in lower 
grades (G1 \& G2) but not in grade 3 tumors $(\mathrm{P}=0.05)$. These data were mimicing those mentioned by Sapino et al., ${ }^{(10)}$, who, as well, significantly correlated the tumor divergent differentiation with the clinical follow-up. Such multidirectional capacity, detected in the other $\operatorname{organs}^{(6.17)}$, is maintained in case of NEbreast carcinomas by cells of well differentiated tumors and being greatly minimized by the poorly differentiated cells. In addition, they found that one of the most important parameters for a favourable prognosis was the ER expression $(\mathrm{P}=$ 0.001 ), being highly correlated with a long overall survival, followed by PR expression $(\mathrm{P}=0.02)$.

Finally, ER \& PR coexpressed only in $45 \%$ of the studied NE-tumors compared to their coexpression in all control cases $(100 \%)$, although in the latter, the $\mathrm{ER}+/ \mathrm{PR}+$ immunoreactive cells were sporadic and smaller in number. This finding was approximated that reported by Clarke et al., ${ }^{(12)}$ and Birsak et al., ${ }^{(18)}$ suggesting that the tumor cells escape the normal growth control by sex steroid hormones.

In conclusions, the present $\mathrm{NE}$ cases coexpressing ER \& PR may be a good example of multidirectional differentiation of the breast neoplasms since this differentiation with the production of NEand exocrine protein is rather a frequent phenomenon in tumors of endocrine organs $(6,17,19)$.

In addition, our results indicate that NE-breast carcinomas, recognized as tumors producing high level of NE-markers, are specific entity and demonstrate that the pathologists should specify the histologic grade as well as the ER \& PR expression, which had been established to be important parameters in the evolution of these tumors. Moreover, since the patients with NE-tumors containing both the ER and the PR had the greatest probability of responding to endocrine therapy and had a better prognosis than those having tumors without these steroid receptors ${ }^{(20)}$, the presence of these receptors and their responsiveness to hormonal treatment might be a guide for therapeutic measures. Further extensive studies are recommended together with attempts at correlation with survival, before trying hormonal therapy as adjuvant treatment modality in NE-breast carcinoma patients with high receptor levels.

\section{References:}

1. Scopsi L., Andreola S., Pilotti S. \& Testori A. (1992): Argyrophilia and granin (Chromogranin/ secretogranin) expression in female breast carcinomas: Their relationship to survival and other disease parameters. Am. J. Surg. Pathol; 16:561-76.

2. Pagani A., Sapino A., Eusebi V. \& Bergnolo, P. (1994): PIP/GCDFP-15 gene expression and apocrine differentiation in carcinoma of the breast. Virchows Arch.; 425: 459-65.

3. Sapino A., Righi L., Cassoni P. \& Papotti M. (2000) : Expression of the neuroendocrine phenotype in carcinomas of the breast. Semin. Diagn. Pathol.; 17: 127-37.

4. Nesland JM, Memoli VA., Holm R. and Gould VE. (1985): Breast carcinomas with neuroendocrine differentiation Ultrastruct. Pathol., 8: 225-40.

5. Travis WD, Colby TV, Corrin B, Shimosato Y. \& Brambilla E. (1999): Histological typing of lung and pleural tumors. World Health Organization international histological classification of tumors $3^{\text {rd }}$ ed. New York. Springer.

6. Di Sant' Agnese PA (2000): Divergent neuroendocrine differentiation in prostatic carcinoma. Semin. Diagn. Pathol.; 17: 149-61.

7. Sapino A., Righi L., Cassoni P. \& Papotti M. (2001): Expression of apocrine differentiation markers in neuroendocrine breast carcinomas of aged women. Mod. Pathol., 14 (8): 768-76.

8. Sapino A., Papotti M., Pietriblasi F., Bussolati F. \& Bussolati G. (1998): Diagnostic cytological features of neuroendocrine differentiated carcinoma of the breast. Virchows Arch; 433: 217-22.

9. Shin SS, Delellis RA, Ying L, Rosen PP. (2000): Small cell carcinoma of the breast: A clinicopathologic and immunohistochemical study of nine patients. Am. J. Surg. Pathol.; 24: 1231-8.

10. Sapino A, Papotti M, Righi L, Cassoni P, Chiusa L (2001): Clinical significance of neuroendocrine carcinoma of the breast. Annals of Oncology; 12 (Suppl.2):115-17.

11. Speirs V, Skliris GP, Burdall SE, Carder PJ (2002): Distinct expression patterns of ER in normal human mammary gland. J. Clin. Pathol; 55: 371-4. 
12. Clarke R, Howell A, Potten C, Anderson E. (1997): Dissociation between steroid receptor expression and cell proliferation in the human breast. Cancer Res; 57: 155-62.

13. Russo J, Ao X, Grill C, Russo IH (1999): Pattern of distribution of cells positive for estrogen and progesterone receptors in relation to proliferating cells in the mammary gland. Breast Cancer. Res. Treat; 53: 217-27.

14. Elston CW and Ellis IO (1991): Pathological prognostic factors in breast cancer. The value of histological grade in breast cancer: Experience from a large study with long term follow up. Histopathology; 19: 403-10.

15. Gateley CA, Bundred NJ (1991): Apocrine breast carcinoma. Am. J. Clin. Pathol., 95: 903-5.

16. Giovanella L, La Rosa S, Ceriani L (1999): Chromogranin $A$ as a serum marker for neuroendocrine tumors: Comparison with neurone specific enolase and correlation with immunohistochemical findings. Int. J. Biol. Markers.; 14: 160-6.

17. Brambilla E, Lantuejoul S, Sturm N (2000): Divergent differentiation in neuroendocrine lung tumors. Semin. Diagn. Pathol.; 17: 138-48.

18. Birsak CA, Janssen PJ, Van Vroonboven CC, Peterse (1996): Sex steroid receptor expression in carcinoid tumors of the breast. Breast Cancer Res. Treat.; 40: 243-9.

19. Capella C, La Rosa S, Uccella S, Billo P. (2000): Mixed endocrine-exocrine tumors of the gastrointestinal tract, Semin. Diagn. Pathol.; 17 : 91-103.

20. Anderson E (2002): The role of estrogen and progesterone receptors in neuroendocrine breast carcinomas. Breast Cancer Res.; 4: 197-206. 


\section{إظهار مستقبلات الاستروجين والبروجستيرون بالكيمياء النسيجية

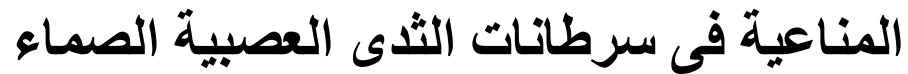

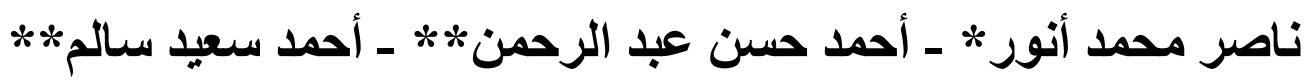
عبد الغنى عوض عيسى *** ***

من أقسام الباثولوجي*،*** و الجر احة العامة*** بكلية الطب بنين جامعة الأزهر فرعى القاهرة وأسيوط

تعرف سرطانات الثذى العصبية الصماء بإظهار ها الواسع للالالات العصبية

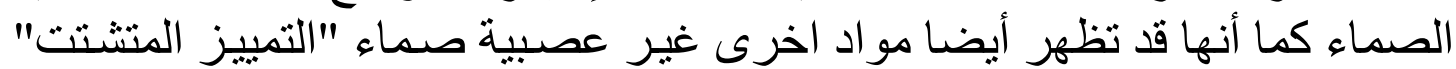

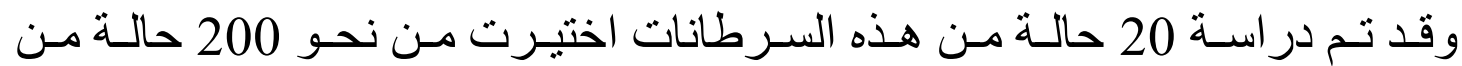

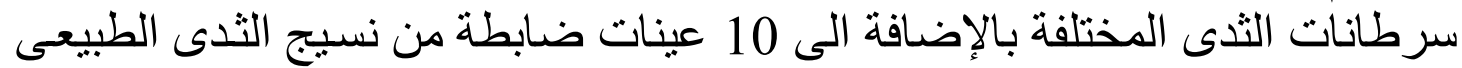

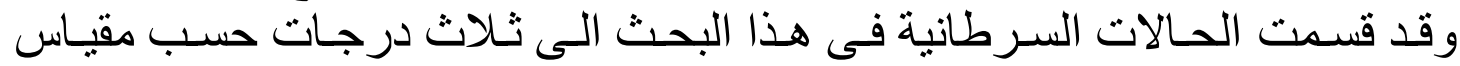

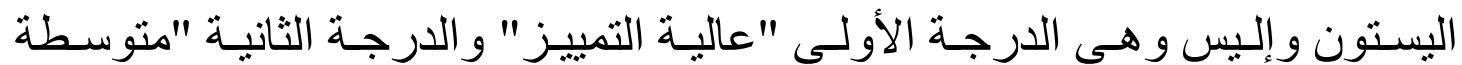

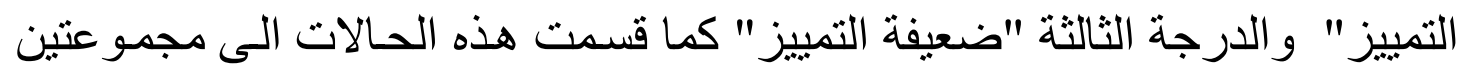

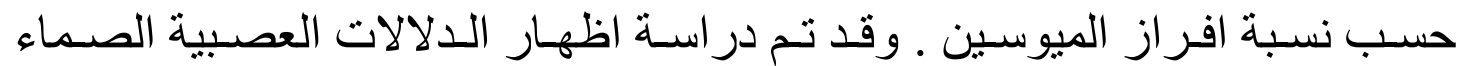
( NSE, CgA)

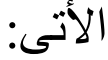

وجود حالات المجمو عة الأولى فى درجة أقل من نظيرتها فى المجمو عة الثانية.

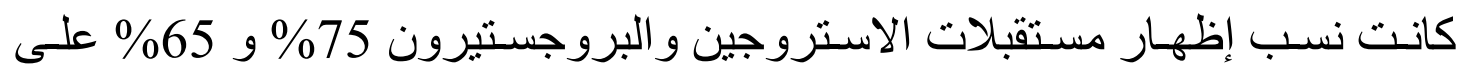

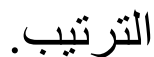

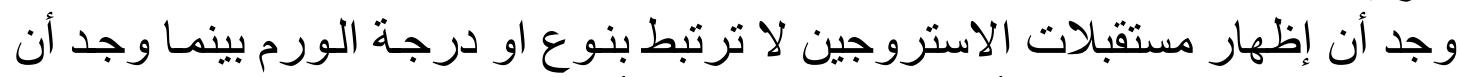

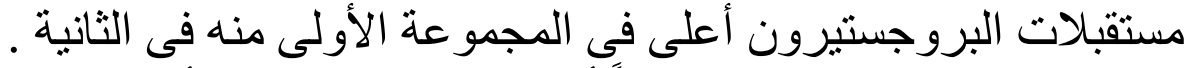

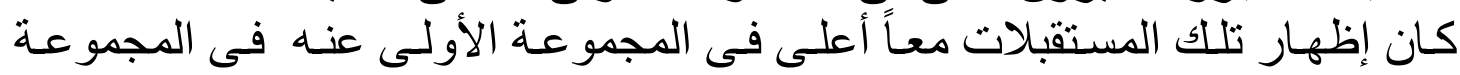

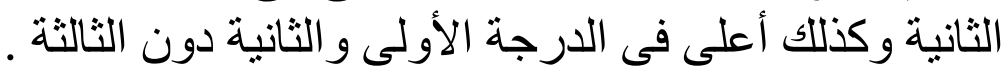

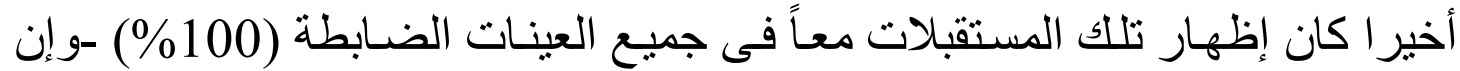

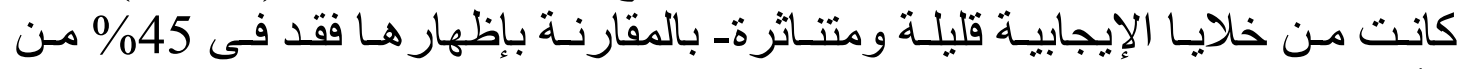

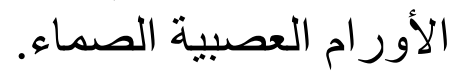

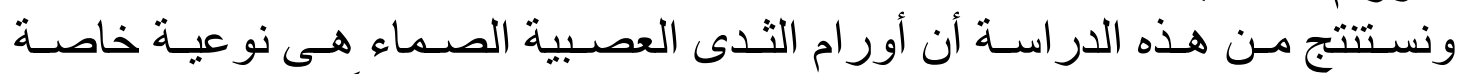

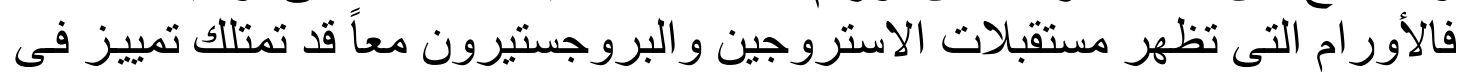

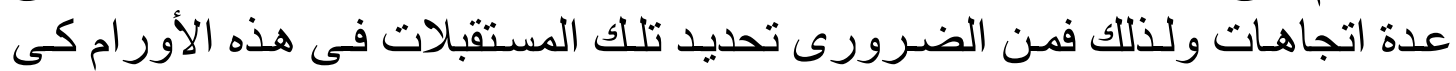

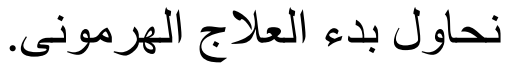

